This is an Accepted Version of the Article published by Elsevier in Journal of Archaeological Science: Reports on 12 June, available online at:

https://www.sciencedirect.com/science/article/abs/pii/S2352409X21002911

\title{
Outlining the knapping techniques: assessment of the shape and regularity of prismatic blades using elliptic Fourier analysis
}

\author{
Mihailo Radinović ${ }^{\mathrm{a}, ~}{ }^{*}$, Irina Kajtez ${ }^{\mathrm{b}}$ \\ ${ }^{a}$ Laboratory of Bioarchaeology, Faculty of Philosophy, University of Belgrade, Čika \\ Ljubina 18-20, 11000 Belgrade, Serbia \\ ${ }^{\mathrm{b}}$ Faculty of Geography, University of Belgrade, Studentski trg 3, 11000 Belgrade, Serbia \\ * Corresponding author. \\ e-mail: mradinovic@gmail.com (M. Radinović).
}

\begin{abstract}
An important aspect of prismatic blade production is the choice of a knapping technique. This study tests the utility of elliptic Fourier analysis (EFA) for discriminating between different knapping techniques and offers a new perspective on blade variability. Our results indicate that there is an overlap in the outline shape and symmetry of individual blades produced by direct percussion, indirect percussion, and pressure debitage. Nevertheless, the EFA points out certain group-level differences regarding the shape and regularity of blade outlines and yields classification accuracy which is comparable to the previously proposed quantitative approaches for distinguishing blades produced by different knapping techniques. However, a more detailed analysis of technique-related factors shows that the emerging variability of blade outlines is more complex and that tripartite division might not always be suitable for reconstructing the past knapping behavior. We discuss the advantages and disadvantages of this method, and how it
\end{abstract}


could complement the standard technological analysis in exploring and explaining blade variability.

Keywords: prismatic blades, knapping technique, outlines, geometric morphometrics, elliptic Fourier analysis, shape, regularity

\section{Introduction}

Laminar technology is characterized by recurrent production of prismatic blades, elongated (length/width > 2) and thin blanks with roughly parallel or slightly converging lateral edges and dorsal ridges (Bar-Yosef and Kuhn, 1999). Although blade production sporadically appears before the European Upper Paleolithic (see Bar-Yosef and Kuhn, 1999; Delagnes and Meignen, 2006; Johnson and McBrearty, 2010; McBrearty and Brooks, 2000; Shimelmitz et al., 2011; Wilkins and Chazan, 2012 and references therein), it became a dominant technology in Europe and Western Asia during this period. Since the Upper Paleolithic, it was continuously employed in different regions until the late prehistory. A common explanation for the ubiquity of blades in the archaeological record lies in their suitability for the insertion in composite tools, due to their standardized shape and dimensions (Bar-Yosef and Kuhn, 1999; McBrearty and Brooks, 2000, p. 495).

The variability of blade blanks is related primarily to the method and technique of production (Inizian et al., 1999, p. 30; Pelegrin, 1990). The method refers to the organization of removals during the knapping process and is generally studied using the refitting or "technological reading" of the knapping products. Another relevant aspect of production is the knapping technique used for blade detachment, which relates to the manner of application of force, types of the tools used, as well as body position and the movement during the knapping process. Three main knapping techniques are considered to have been used for obtaining blades - direct percussion, indirect percussion, and pressure debitage (e.g. Inizian et al., 1999, p. 71). In direct percussion, the core is held in one hand, while the blow is applied directly to the core with the other hand using a hammer made of stone, antler, or wood. Indirect percussion involves the use of an intermediate element (punch), which is placed on the core and then struck with the hammer. Lastly, in pressure knapping a pressure tool is placed on the core and the pressure is applied until the blade is detached. Pelegrin (2012) distinguishes five modes of pressure debitage, depending on the types of tools used and the position and movement of the knapper. 
While mode 1 involves pressure debitage of blades using a hand-held tool, other modes are characterized by the use of more elaborate tools to apply the pressure - shoulder crutch (mode 2), abdominal crutch in a sitting (mode 3 ) or standing position (mode 4), and lever (mode 5). Timing the appearance and spread of different knapping techniques is important for studying the technology of knapped stone tools, diffusion of innovations, craft specialization, and division of labor (Pelegrin, 2012; Perlès, 2001), etc.

Various technical stigmata were proposed for distinguishing between the blades produced by different knapping techniques (e.g. Crabtree, 1968; Damlien, 2015; Debenath and Dibble, 1994; Driscoll and García-Rojas, 2014; Inizian et al., 1999; Kooyman, 2000; Magnani et al., 2014; Pelegrin, 2012; Sollberger and Patterson, 1976; Sørensen, 2006; Soriano et al., 2007). Most of them are qualitative morphological features, which can be classified into general morphological characteristics (e.g. regularity, distal end termination, profile type), and detachment and platform attributes (e.g. platform, lip, bulb features, ripples) (Pelegrin and Inizan, 2013). Linear measurements (e.g. maximal length, width, platform thickness), indices (elongation index; parallel index, Davidson, 2003), angles, and other measures (Boldurian and Hoffman, 2009) are also used for describing blade variability.

Based on the data gathered from knapping experiments, it is argued that certain diagnostic features are typical of blades produced using specific techniques. However, probably due to complex interplay of factors (e.g. raw material properties, core morphology, angle of blow, striking platform preparation, indentor type, individual factors) (e.g. Archer et al., 2018; Clarkson and Hiscock, 2011; Cotterell and Kamminga, 1987; Dibble and Rezek, 2009; Dibble and Whittaker, 1981; Driscoll and García-Rojas, 2014; Lengyel and Chu, 2016; Magnani et al., 2014; Muller and Clarkson, 2014; Pelcin, 1997a, 1997b, 1997c; Rezek et al., 2011; Williams and Andrefsky, 2011), there is an overlap between the morphological features of blades produced by different techniques (e.g. Damlien, 2015; Kooyman, 2000; Sollberger and Patterson, 1976). Thus, it is often acknowledged that the differences should be observed on the assemblage level.

Recognition of knapping techniques is a largely subjective endeavor, which relies on observation, recognition, experience, practice, etc. (Inizian et al., 1999, p. 90). Such an approach is suitable for experts with large experimental collections and years of knapping experience (Clark, 2012; Inizian et al., 1999; Pelegrin, 2006). For many researchers, training to master all 
specific skills (e.g. lever pressure) is not feasible due to the time, resources, and practical knowledge needed to acquire them. Thus, the reliability of some subjective interpretations should be assessed, as blind tests indicate relatively high error rates and inter- and intra-analyst variation for recognizing certain knapping behaviors (e.g. Byrne et al., 2016; Ruck et al., 2020).

Recently, a quantitative methodology was employed for distinguishing between the blades produced by different knapping techniques. Damlien (2015) analyzed several technological features to describe the blades and then applied Linear Discriminant Analysis (LDA) to try to discriminate between the knapping techniques. This study has inferred that there is an overlap in the morphological characteristics of individual blades produced by different techniques (direct soft organic, direct soft stone, direct medium hard stone, indirect, pressure), with the overall cross-validated correct classification rate of $54.5 \%$. The classification rate varied for different techniques but generally indicated a relatively low prediction rate for individual blades. However, Damlien suggested that technique-related changes on the assemblage level can be more formally assessed using this approach. Yet, despite sophisticated statistical analyses used for making inferences, it still largely relies on descriptive attributes, where data comparability between studies can be questionable.

Thus, discipline would benefit from transparent and reproducible methods that are widely applicable in distinguishing between the knapping techniques. During the last decade, geometric morphometrics (GMM) approaches have been more commonly applied to various forms of material culture, including knapped stone artifacts (Okumura and Araujo, 2019). GMM is a quantitative approach to shape analysis, where the shape is defined as "geometric properties of an object that are invariant to location, scale, and rotation" (Slice, 2005, p. 3). It overcomes certain issues related to qualitative attributes and linear measurements (Zelditch et al., 2012), analyzing a large number of features and their relationships simultaneously, facilitating replicability, and offering easily interpretable visualizations. The utility of GMM is evidenced by previous studies - it has contributed to the understanding of the variability of different types of stone artifacts, such as cores (e.g. Lycett et al., 2010; Lycett and von Cramon-Taubadel, 2013), handaxes (e.g. Herzlinger et al., 2017; Hoggard et al., 2019; Iovita and McPherron, 2011), points (e.g. Archer et al., 2015; Buchanan et al., 2014; Costa, 2010; Fox, 2015), and flakes (e.g. Archer et al., 2018; Borel et al., 2017, 2013; Byrne et al., 2016; Picin et al., 2014) 
Here we present a pioneer application of GMM to prismatic blades. Our main objectives are to quantitatively examine differences between the blades produced by different knapping techniques and to assess the discriminating power of this approach for the recognition of the knapping techniques. For this purpose, we analyzed the shape and bilateral symmetry of blade contours using elliptic Fourier analysis (EFA). The presented approach examines several previously proposed morphological features of blades (e.g. blade elongation, location of maximum width). We also focused on blade regularity, as researchers (e.g. Damlien, 2015; Inizian et al., 1999; Pelegrin, 2006; Sørensen, 2006) have suggested that blades obtained by indirect percussion and pressure flaking are more regular than blades produced by direct percussion, while pressure blades are the most regular having "...the extreme regularity of the edges and ridges..." (Pelegrin, 2006, p. 42). However, these claims have not been quantitatively evaluated. Based on these previous insights, we formulated a research hypothesis and a null hypothesis:

$\mathbf{H}_{\mathbf{0}}$. Blades produced by different knapping techniques do not differ in terms of regularity, i.e. there are no differences between the groups of blades regarding their levels of bilateral symmetry and shape variance.

$\mathbf{H}_{1}$. Blades produced by indirect percussion are more regular than those produced by direct percussion, having lower variance in shape and higher levels of bilateral symmetry. Blades

produced by pressure debitage are the most regular among the three knapping techniques, having the lowest variance in shape (i.e. being most standardized) and the highest levels of bilateral symmetry.

Finally, we explored how two other factors (size, mode of pressure) affect the blade shape and symmetry.

\section{Materials and methods}

\subsection{Sample}

Outline analysis was conducted on photographs of 228 experimentally produced blades from the published articles, where the knapping technique was reported (Lengyel and Chu, 2016; Muller et al., 2017; Pelegrin, 2012; 2006; Sørensen, 2006) (Table 1). Blades from these five publications were produced by three or four medium to expert knappers (it is not certain if the 
blades from Muller et al. 2017 are produced by C. Clarkson or J. Pelegrin). The skill level of M. Sørensen is not explicitly stated, but we consider him to be at least a medium-level knapper based on the range of knapping abilities demonstrated (Sørensen, 2006). All four knappers are right-handed, as inferred from the published photos and online videos of knapping by these researchers. All the images show dorsal sides of blades, with the proximal end in the upper part of the image. To avoid differences related to raw materials, only flint blades were analyzed. We excluded fragmented blades, except slightly damaged and properly refitted blades. The majority of blades are produced by pressure debitage (177), and much less by direct (31) and indirect percussion (20). The ID of each blade, the knapping technique used to produce it, as well as other relevant data about the blades - knapper, skill level, handedness, mode of pressure for pressure debitage, indentor type, maximal length in $\mathrm{mm}$, publication, figure - are stored in a database (Supplementary material 1).

\begin{tabular}{|c|c|c|c|c|c|}
\hline Reference & Figures & $\begin{array}{c}\text { No. of blades } \\
\text { selected }\end{array}$ & Knapper & Handedness & Skill level \\
\hline Lengyel, Chu, 2016 & Fig. 4 & 12 & G. Lengyel & right & medium \\
\hline Muller et al., 2017 & Fig. 1 & 7 & $\begin{array}{c}\text { C. Clarkson/ } \\
\text { J. Pelegrin }\end{array}$ & right & expert \\
\hline Pelegrin, 2006 & Figs. 1,2 & 22 & J. Pelegrin & right & expert \\
\hline Pelegrin, 2012 & $\begin{array}{c}\text { Figs. 18.3, 18.5, } \\
18.7,18.9,18.11\end{array}$ & 138 & J. Pelegrin & right & expert \\
\hline Sørensen, 2006 & Figs. 2, 4-8 & 49 & M. Sørensen & right & medium/expert? \\
\hline
\end{tabular}

Table 1. General information about the blade dataset analyzed in this study.

In 2D GMM, measurement errors can be produced during the image acquisition, digitization of coordinates, but also due to flattening of the third dimension (e.g. Arnqvist and Mårtensson, 1998; Cardini, 2014; Cardini and Chiapelli, 2020; Fruciano, 2016; Navarro and Maga, 2016). In our dataset, images from different publications might have been taken using different resolution, magnification, focal length, object distance, and other aspects of image acquisition that could have influenced the precision of outline digitization. Furthermore, distortions can be produced due to differing blade length and blade curvature. Thus, we explored how several imaging options affect the outline shape and symmetry of blades (Supplementary material 2), inferring that the measurement error primarily affects the bilateral symmetry of prismatic blades. Our preliminary results indicate that the measurement error produces some amount of random noise 
in this aspect, and should not significantly influence the comparisons among groups. Thus, we proceeded with our preliminary study, which aims to make a robust assessment of variability in shape and symmetry, and initiate further research in this field.

\subsection{Elliptic Fourier analysis (EFA)}

For analyzing the blade variability from the published photographs, we opted for outline analysis using EFA (Kuhl and Giardina, 1982), which is suitable for "landmark-poor outlines" (Crampton, 1995, p. 180). EFA is the most commonly used method for analyzing the closed contours of the plane or almost plane objects, as it offers certain advantages over other methods (e.g. Crampton, 1995; Riede et al., 2019; Sheets et al., 2006). Detailed explanations of the conceptual framework behind the EFA were published elsewhere (e.g. Caple et al., 2017; Ferson et al., 1985; Kuhl and Giardina, 1982; Lestrel, 1997). EFA is a method based on the Fourier transformations, where closed contours are decomposed into a series of mathematical functions (harmonics) - sets of sines and cosines and their corresponding harmonic coefficients. Each harmonic is a function that describes the elliptic shape and is defined by four coefficients, two for $\mathrm{x}$ and two for $\mathrm{y}$ coordinate. The lower-order harmonics describe the general shape, while the higher-order harmonics are related to fine-scale details of outlines. Although the complete description of outlines can be described with an infinite number of harmonics, reasonable approximations of the original shape (e.g. 99\%) can be made using a limited set of coefficients. By retaining a certain number of harmonics and corresponding coefficients, outlines can be compared in a quantitative manner using multivariate statistics.

The bilateral symmetry (i.e. object symmetry, see Klingenberg, 2015) of outlines can also be analyzed using EFA (Iwata et al., 1998), calculated as a ratio of symmetric coefficients and the absolute sum of coefficients. In this study, the bilateral symmetry measures how much the left and right halves of blades are mirror-images of each other. The value of symmetry ranges between 0 and 1, with the value of 1 indicating perfect bilateral symmetry.

\subsection{Procedures}

After editing the photographs, we used Corel Draw Graphic Suite X7 to create vector outlines. Following the procedure from Hoggard et al. (2019), blades were selected using the Outline trace function, the boundary around them was added and set to a thickness of 1 pixel, and the 
underlying photo erased. The background color was set to white, and the images were exported as .png files. After this step, the .tps file was created using tpsUtil 1.78 (Rohlf, 2019) for storing blade outline coordinates (Supplementary material 3). Subsequently, outlines were traced and digitized in tpsDig 2.31 (Rohlf, 2017) using the Outline object function, by taking 3000 equally distanced points in a clockwise direction, starting from the proximal part of blades.

For all further data manipulation and analyses (Supplementary material 4) we used $\mathrm{R}$ programming software v. 3.6.3 (R Core Team 2020), modifying the code by Hoggard et al. (2019) and using the following packages: Momocs v.1.3.2. (Bonhomme et al., 2014), ggplot2 v. 3.3.3 (Wickham, 2016), cowplot v. 1.1.1 (Wilke, 2020), reshape2 v. 1.4.4 (Wickham, 2007), vegan v. 2.5-7 (Oksanen et al., 2020), pairwiseAdonis v. 0.0.1 (Martinez Arbizu, 2017), dplyr v. 1.0.3 (Wickham et al., 2021), cvequality (Marwick, Krishnamoorthy 2019). The .tps file was imported and joined with a database containing the metadata (Supplementary material 1). To normalize the blade outlines, the effect of location (by setting the common centroid) and size (by setting equal centroid size) were removed using coo_center and coo_scale functions from the Momocs package, while rotation differences were eliminated by the elliptic fitting of the first harmonic. This way, correspondence between overall the outline morphology of blades is achieved. To determine the number of harmonics which describes $99.9 \%$ of outline shape, we used the calibrate_harmonicpower_efourier function from the Momocs package, which indicated that the first 20 harmonics describe $99.9 \%$ of the total harmonic power. Thus, we retained 20 harmonics and their corresponding coefficients for further analyses. The symmetry values for blades were obtained using the symmetry function in the Momocs package.

\subsection{Statistical analyses}

To examine the shape variability, we first performed the Principal Component Analysis (PCA) on Fourier coefficients. To test whether the three groups of blades (direct, indirect, pressure) differ in shape, Permutational Multivariate Analysis of Variance (PERMANOVA) was conducted on the first 15 principal components, and p-value estimated based on 10000 permutations, while noting that it might be somewhat liberal for unequal sample sizes (Anderson and Walsh, 2013). For this and other statistical tests, we used non-parametric alternatives as the assumptions of normality and homoscedasticity were continuously violated. Subsequently, 
pairwise PERMANOVA was conducted to test the differences between the individual groups, with Bonferroni-corrected p-values.

To evaluate the accuracy of the method in discriminating between the blades produced by different techniques, and compare it with the accuracy of the previously proposed approaches (Buchanan et al. 2016; Damlien 2015), we conducted a Linear Discriminant Analysis (LDA). The LDA was also performed on the first 15 PCs that cumulatively explain $99 \%$ of the shape variability, as this procedure is suitable for reducing the number of variables and collinearity between them prior to analysis, without losing relevant information and influencing the results (Kovarovic et al., 2011; Zelditch et al., 2012). Leave-one-out (Jack-knife) method was used as a measure of correctly classifying individual blades according to the knapping technique. To avoid correct classifications by chance (i.e. over-fitting) (Kovarovic et al., 2011), equal group sizes were created by randomly selecting 20 blades (the minimum common group size) produced by indirect percussion and pressure debitage. This procedure was repeated 10000 times, and the range of cross-validated values was reported.

To address the research hypotheses regarding the blade regularity, we first calculated the multivariate Euclidean distance of each blade from the centroid of the corresponding group (e.g. Herzlinger and Grosman, 2018), using the first 15 PCs. Obtained values, which could be considered as multidimensional measures of dispersion from the mean shape, were visualized using a box-plot, and were subjected to the Kruskal-Wallis test, followed by the Mann-Whitney $\mathrm{U}$ test with Bonferroni correction for pairwise comparisons. Additionally, for the three groups of blades the coefficient of variation $(\mathrm{CV}=$ standard deviation / mean *100) values were calculated for each of the first three PCs (i.e. shape variables). As the PC values can be negative, before calculating $\mathrm{CVs}$ we normalized them using the min-max normalization function to a range between 1 and 10, following Wang and Marwick (2020). To compare the equality of CVs among the knapping techniques, we employed the modified signed-likelihood ratio (MSLR) test (Krishnamoorthy and Lee, 2014). For comparing the symmetry of blades produced by different knapping techniques, we calculated summary statistics and visualized the symmetry values using a box-plot diagram. Kruskal-Wallis test was conducted for determining if there are significant differences in the symmetry between the three groups. Mann-Whitney $U$ tests were subsequently employed for pairwise comparisons, with Bonferroni-corrected p-values. 
Additionally, we explored the effect of two other factors on blade shape and symmetry. Firstly, we examined the correlation between the size (blade length) and both shape (main principal components) and symmetry, both visually and using the Spearman's rank correlation coefficient. However, as our blade dataset did not include larger blades that can be produced by direct percussion (Pelegrin, 2006), no statistical tests were done and these results should be taken with some caution. Secondly, in the case of pressure debitage we observed the influence of mode of pressure on blade variability, with the following sample sizes: mode 1 - 22; mode 2 - 24, mode 3 - 73; mode 4 - 23; mode 5 - 35. We made only visual assessments of the possible patterns.

All the supplementary files are available at the Open Science Framework platform (https://doi.org/10.17605/OSF.IO/HGESZ).

\section{Results}

\subsection{Morphology}

The first three principal components account for $94.2 \%$ of the total variability: PC1 $-81.6 \%$, PC2 - 7.9\%, PC3 - 4.6\%. The PC1 relates to general narrowness (elongation), PC2 to bilateral (side-to-side) symmetry, and PC3 to the distribution of width across the blade length (Figure 1). The biplots of the pairs of the first three axes (Figure 2) with convex hulls show an overlap in the shape of blades produced by different techniques. However, convex hulls and group centroids point to certain group-level differences along the PC1 - blades produced by indirect percussion are generally narrower than those using direct percussion, while the pressure blades are the narrowest, apart from the certain number of outliers. The mean shape of three groups of the blades does not differ along the PC2 - it is around zero for each group (non-curved blades) but a higher dispersion of blades produced by direct percussion along this axis indicates that they may be more curved than the blades produced by other techniques. Pressure blades have the lowest dispersion in PC2 among the groups. Shape differences along the PC3 indicate that the majority of blades have similar width of proximal and distal parts. However, some pressure blades have a wider proximal than the distal part, unlike the direct percussion blades that more often have wider distal parts. Indirect percussion blades are slightly less diverse in this aspect and generally have similar proximal and distal width. 


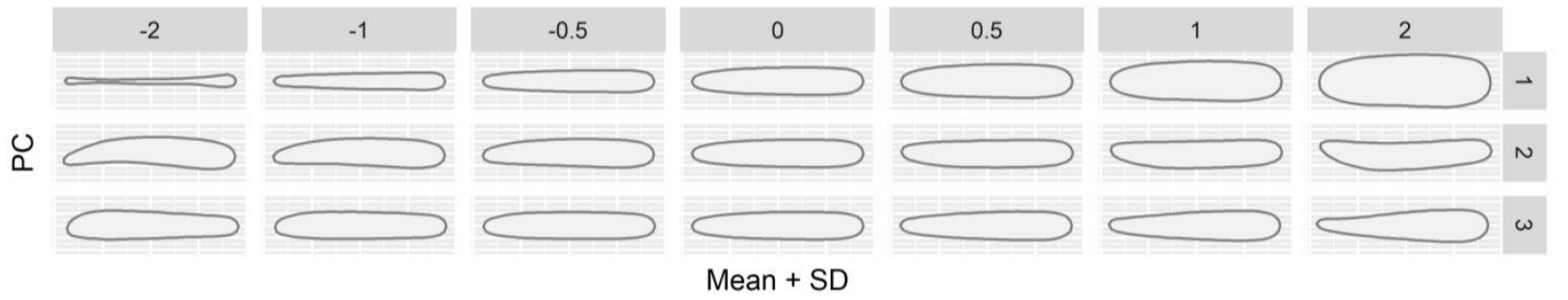

Figure 1. Morphological variation along the first three PCs.

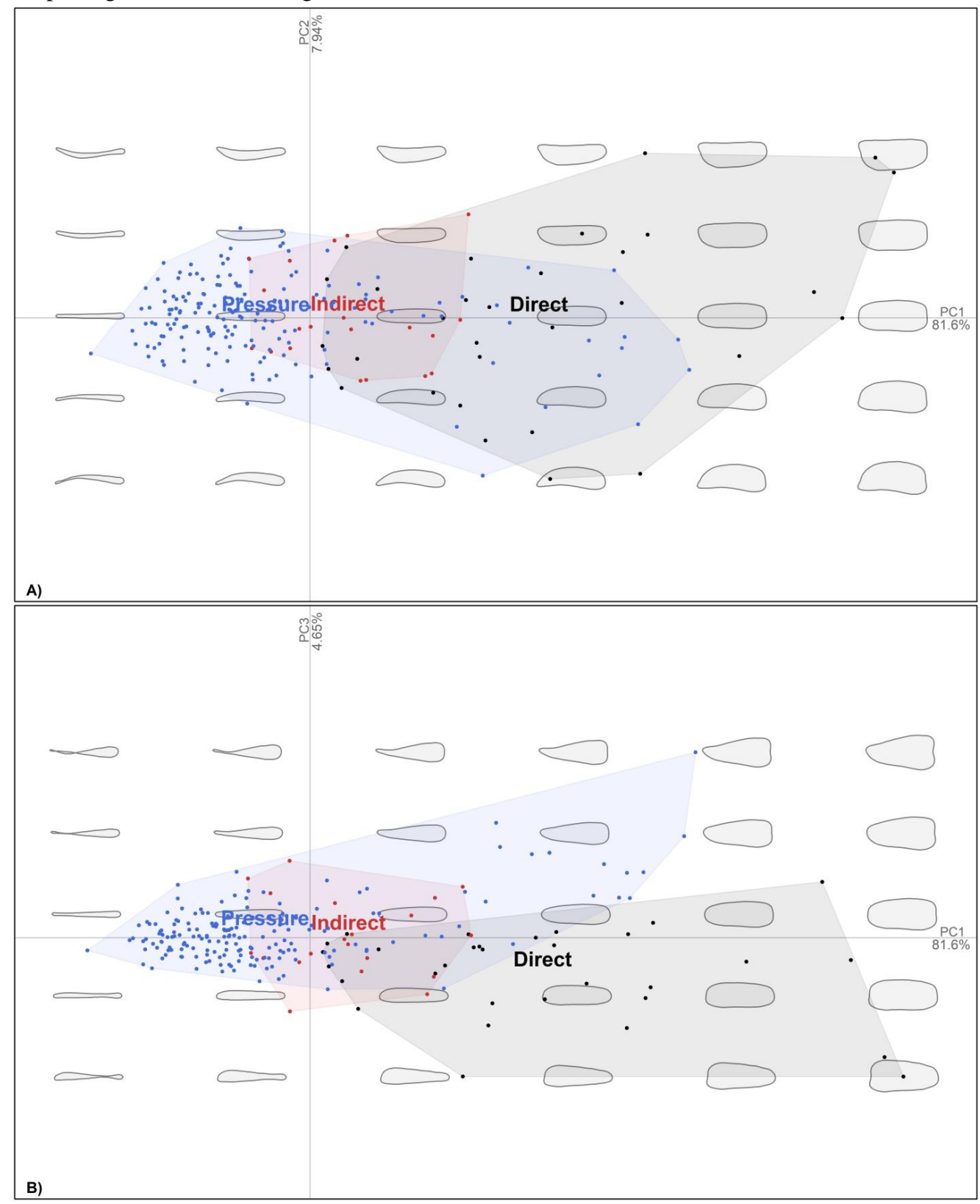

Figure 2. Scatter plots of PC1 and PC2 (a) and PC1 and PC3 (b) showing main shape differences in the sample, with visualization of shape space. Convex hulls and group centroids are shown for each knapping technique - direct percussion (black), indirect percussion (red), pressure debitage (blue). 
Certain morphological differences between the three groups of blades are confirmed by permutational MANOVA test, as the null hypothesis of no difference is rejected $(\mathrm{DF}=2 ; \mathrm{SS}=$ 0.673; MS = 0.336; Pseudo $\mathrm{F}=53.546, \mathrm{p}<0.001$ ), while pairwise PERMANOVA tests (Table 2) show statistically significant morphological differences between all three groups of blades.

\begin{tabular}{|c|c|l|r|r|r|r|}
\hline Pairs & \multicolumn{1}{|c|}{ DF } & \multicolumn{1}{|c|}{ Sums Of Sqs } & \multicolumn{1}{c|}{ F.Model } & \multicolumn{1}{c|}{$\mathbf{R}^{2}$} & \multicolumn{1}{c|}{ p-value } & Adjusted p-value \\
\hline Direct vs Indirect & 1 & 0.152 & 16.04 & 0.247 & $<\mathbf{0 . 0 0 1}$ & $<\mathbf{0 . 0 0 1}$ \\
\hline Direct vs Pressure & 1 & 0.662 & 101.152 & 0.329 & $<\mathbf{0 . 0 0 1}$ & $<\mathbf{0 . 0 0 1}$ \\
\hline Indirect vs Pressure & 1 & 0.041 & 7.884 & 0.039 & $\mathbf{0 . 0 0 4}$ & $\mathbf{0 . 0 1 1}$ \\
\hline
\end{tabular}

Table 2. Summary of pairwise permutational MANOVA tests with knapping technique as the independent variable and the first 15 PCs as dependent

The overall cross-validated correct classification rates of LDA for 10000 sampling repetitions range from 43.3 to $83.3 \%(\bar{x}=65.3 \%$; $\mathrm{M}=65.0 \%$ ) (Figure 3a). Thus, the correct classification rate is always higher than baseline chance probability (33.3\%), but differs according to the knapping technique $\left(\bar{x}_{\text {direct }}=62.5 \% ; \bar{x}_{\text {indirect }}=58.0 \% ; \bar{x}_{\text {pressure }}=75.6 \%\right)($ Figure 3b), being the highest for the pressure blades.
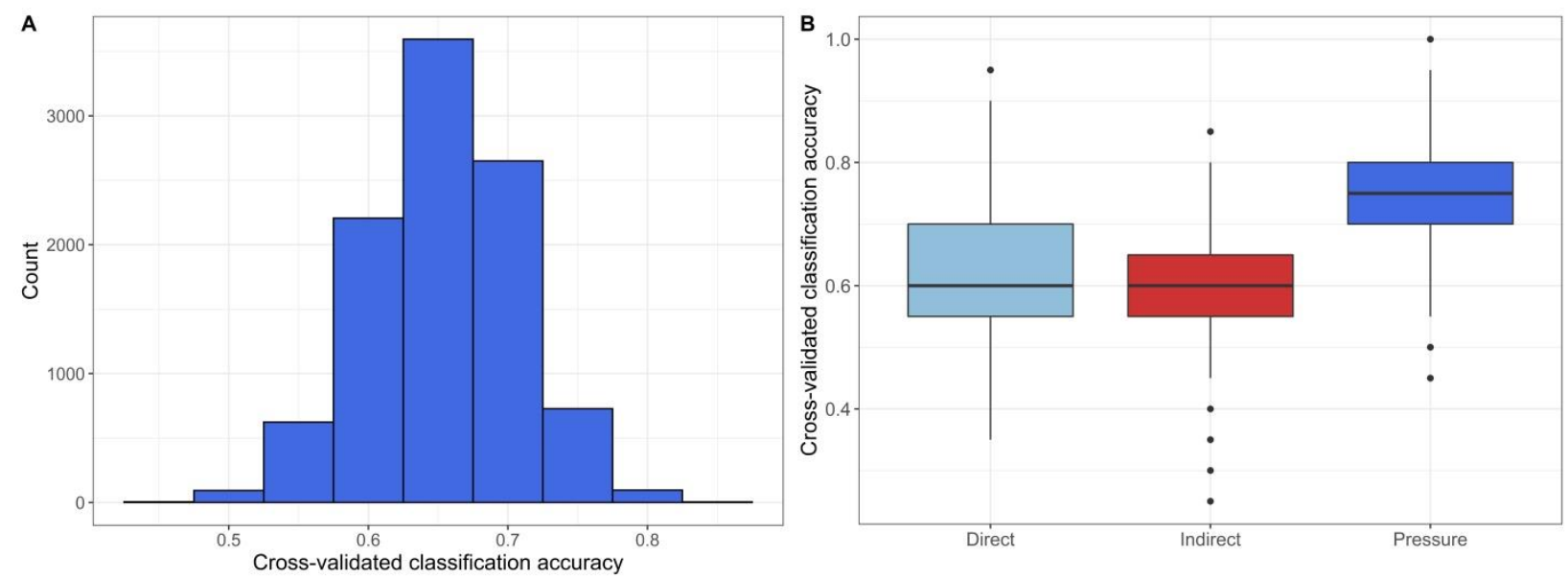

Figure 3. Histogram showing cross-validated classification accuracy of LDA for all blades (a); box-plot showing classification accuracy for individual groups (b). 


\subsection{Regularity}

The box plot of multidimensional Euclidean distances shows that these values are lower for blades produced by indirect percussion and pressure debitage than for direct percussion (Figure 4), indicating that they have lower variability (more standardized outline morphology), apart from a certain number of outliers in the case of pressure debitage. Statistically significant differences in morphological variability of the three groups are indicated by Kruskal-Wallis test $(\mathrm{H}=33.852, \mathrm{DF}=2, \mathrm{p}<0.001)$, while the pairwise comparisons confirmed our insights based on the box-plot (direct-indirect: $\mathrm{p}<0.001$; direct-pressure: $\mathrm{p}<0.001$; indirect-pressure: $\mathrm{p}=$ $0.571)$ - indirect percussion and pressure blades are significantly more standardized than direct percussion blades. Similar trend is visible when the variability of individual shape variables is compared using the coefficient of variation (Table 3). Pressure blades are the most regular in terms of side-to-side symmetry (PC2) and tip-base width ratio (PC3), followed by indirect percussion blades, while direct percussion blades are the least regular in these aspects. However, pressure blades are the least regular regarding the relative width/elongation (PC1). When pairwise comparisons of CVs are made using the MSLR test, the only statistically significant differences are between $\mathrm{CVs}$ of indirect percussion and pressure blades for $\mathrm{PC} 1$; direct percussion and pressure blades for PC2; and direct percussion and pressure blades for PC3.

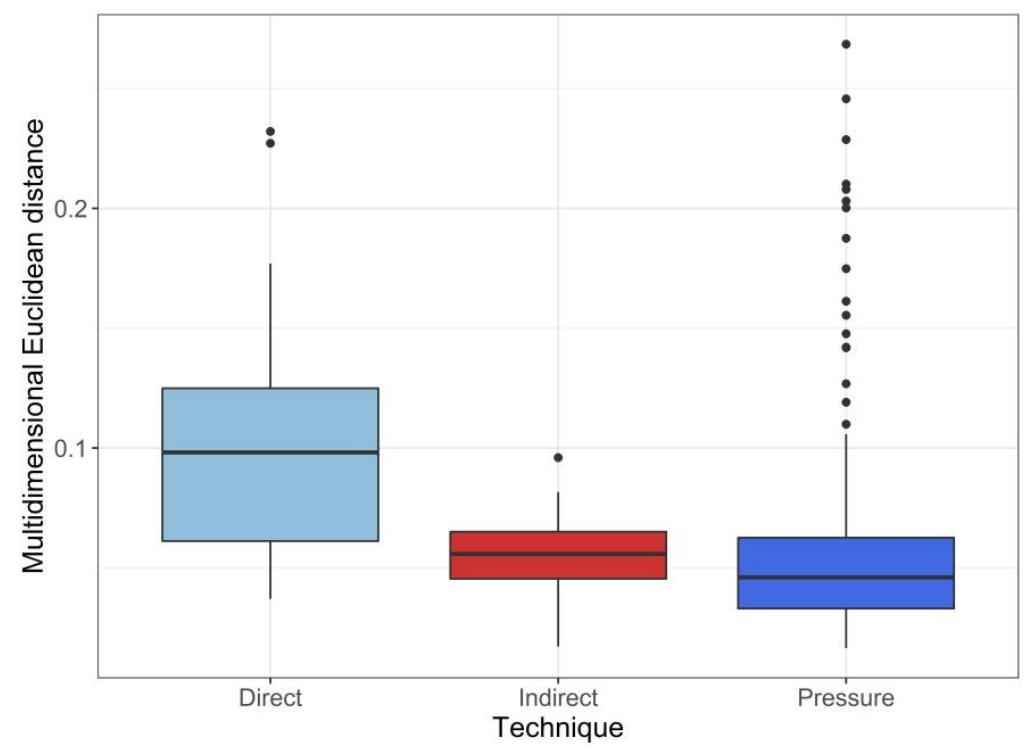

Figure 4. Box-plot showing the distribution of multidimensional Euclidean distances for each group. 
Symmetry values calculated using Fourier coefficients (Table 4; Figure 5) indicate that the blades produced by direct percussion have the lowest mean symmetry, indirect percussion blades somewhat higher, while the pressure blades have the highest symmetry values. Kruskal-Wallis test shows that the null hypothesis of equality of mean ranks can be rejected $(\mathrm{p}<0.001, \mathrm{n}=228$, $\mathrm{DF}=2, \mathrm{H}=57.806)$. Mann-Whitney pairwise tests show that the symmetry of the pressure blades is significantly higher than for the other two techniques (direct-pressure: $\mathrm{p}<0.001$; indirect-pressure: $\mathrm{p}<0.001$ ), while the differences between direct and indirect percussion blades are not statistically significant (direct-indirect: $p=0.135$ ). Coefficients of variation also indicate that pressure blades have lower variance in symmetry values than the other two groups of blades, despite a much larger sample size.

\begin{tabular}{|c|r|c|c|c|c|r|}
\hline Technique & Count & Mean & SD & Min & Max & Coefficient of variation \\
\hline Direct & 31 & 0.922 & 0.029 & 0.860 & 0.961 & 3.101 \\
\hline Indirect & 20 & 0.938 & 0.027 & 0.896 & 0.971 & 2.866 \\
\hline Pressure & 177 & 0.961 & 0.019 & 0.885 & 0.992 & 1.964 \\
\hline
\end{tabular}

Table 4. Summary of symmetry values, calculated using Fourier coefficient, for each knapping technique.

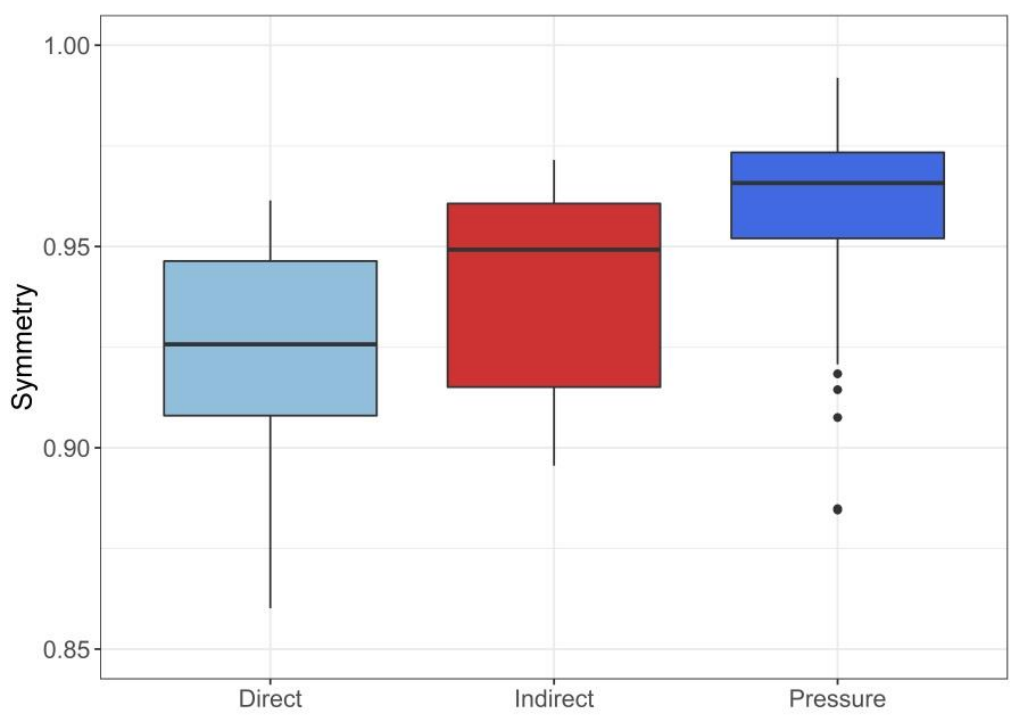

Figure 5. Box-plot showing comparison of the symmetry values, calculated using Fourier coefficient, among the knapping techniques. 


\subsection{Other factors}

To investigate the relationship between size and shape, we first observed a correlation between blade length and PC1/narrowness. Spearman rho (0.503) indicates that there is a moderately strong monotonic relationship between the two, but this relationship differs among the knapping techniques (Figure 6a). Despite a general tendency for longer blades to be narrower, pressure blades are narrower than blades produced by other techniques for each blade length, while direct percussion blades are wider than other blades. However, longer direct percussion blades should be included to confirm this trend. As both PC2 and symmetry values measure the bilateral symmetry, we only examined the correlation between symmetry values calculated based on Fourier coefficients and blade length, which shows a weak positive correlation for this sample ( $\rho$ $=0.16$ ). When comparing groups (Figure $6 \mathbf{b}$ ), both shorter and longer pressure blades are generally more symmetrical than the blades produced by other techniques, while direct percussion blades are the least symmetrical for each blade length. There is a weak negative correlation between blade length and PC3 $(\rho=-0.33)$, indicating that longer blades in our sample generally have somewhat narrower proximal parts compared to distal than shorter blades. Longer blades are also less variable in this shape aspect, having a similar tip-base width ratio (Figure 6c). As mentioned, this relationship differs among groups - for direct percussion blades maximal width is sometimes located in the distal part, while (especially shorter) pressure blades often have wider proximal than distal parts. Indirect percussion blades are less variable regarding the PC3 and can have maximal width in either proximal or distal parts.
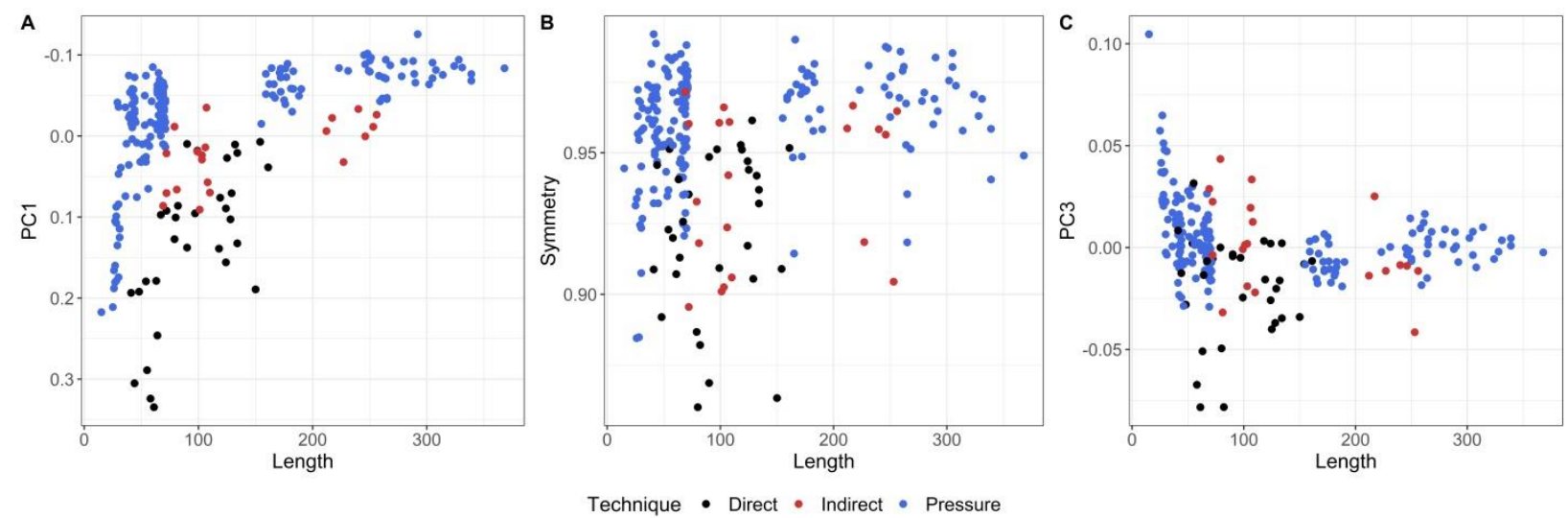

Figure 6. Scatter plots showing the relationship between blade length and a) PC1; b) symmetry calculated using Fourier coefficient; c) PC3. 
When pressure blades are grouped by mode of pressure (Figure 7), it is visible that the blades produced by modes 4 and 5 are quite distinct in terms of shape, being consistently narrow, symmetrical, and standardized. Blades produced by modes 1 and 3 are on average somewhat less narrow and standardized in terms of shape, while mode 2 blades are quite variable and generally wider than blades produced by other modes of pressure, being somewhat more similar to blades produced by other knapping techniques. Similar groupings are visible on the box-plot with symmetry values (Figure 8), where mode 4 and 5 blades are generally the most symmetrical, while mode 2 blades are the least symmetrical.

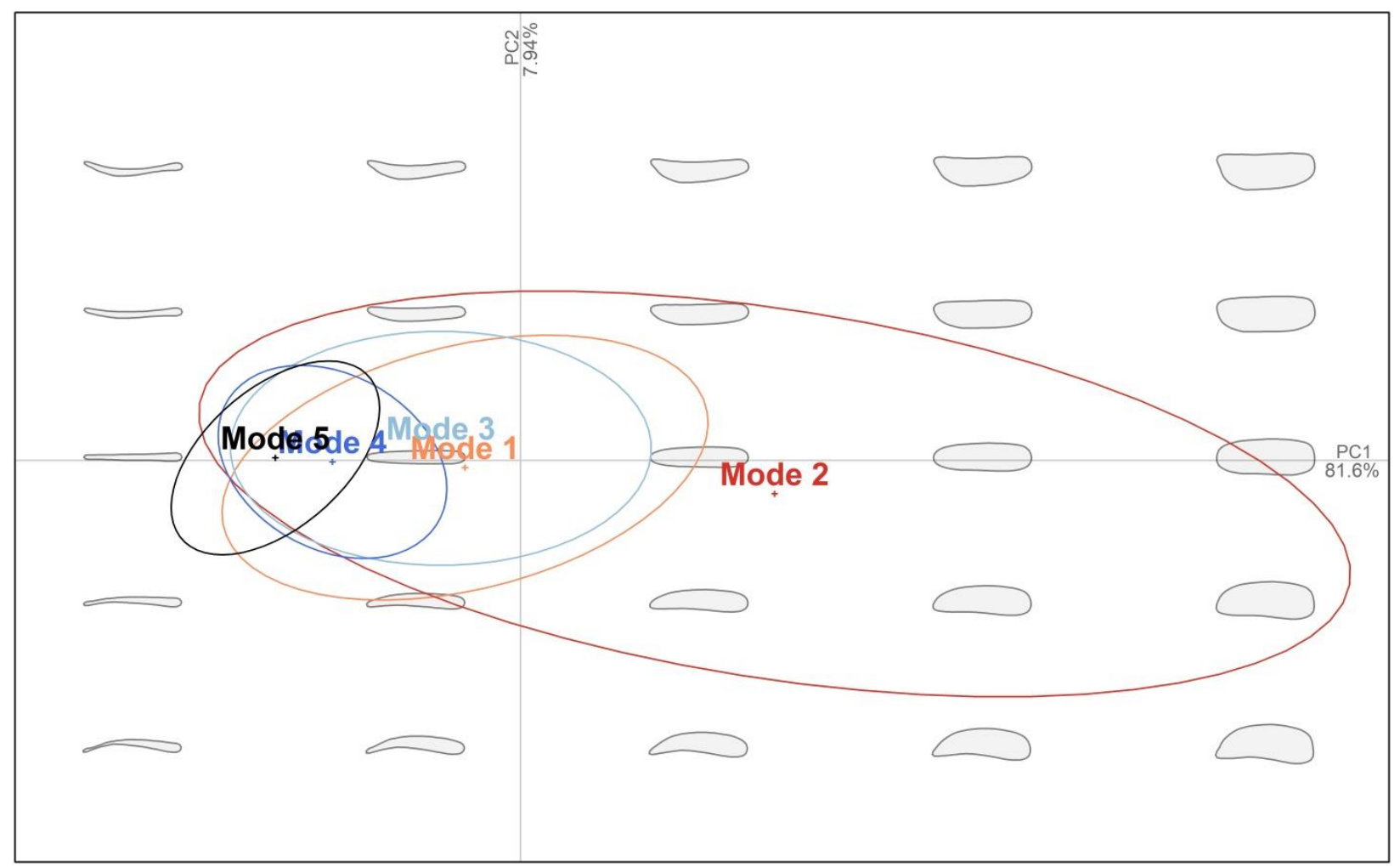

Figure 7. Scatter plot of $\mathrm{PC} 1$ and $\mathrm{PC} 2$ for pressure blades, with visualization of shape space. Confidence ellipses $(95 \%)$ and group centroids are shown for each mode of pressure - mode 1 (orange), mode 2 (red), mode 3 (lightblue), mode 4 (blue), and mode 5 (black). 


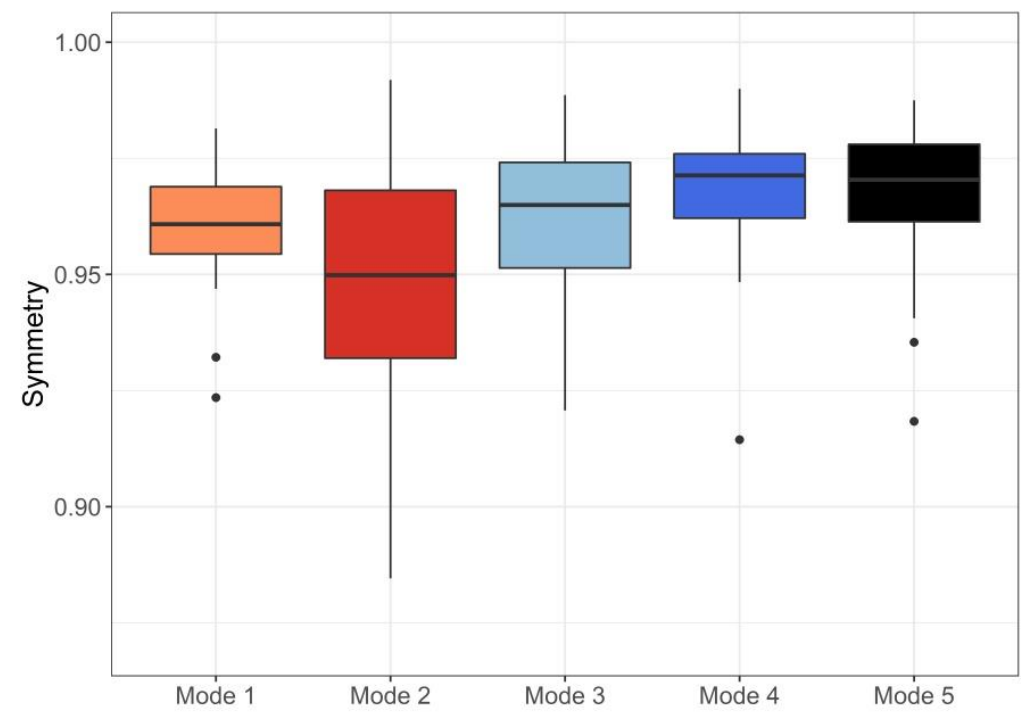

Figure 8. Box-plot showing the comparison of symmetry values, calculated using Fourier coefficient, among the modes of pressure.

\section{Discussion and conclusions}

Here we quantitatively analyzed the outline shape and regularity of prismatic blades to contribute to the description of their variability and to try to differentiate the blades produced by direct percussion, indirect percussion, and pressure debitage. Morphological analysis using EFA has shown that for this sample the major part ( 94\%) of blade outline shape variability can be decomposed into three main features: narrowness/elongation, bilateral symmetry, and tip-base width relationship. Similar main components of shape variability were obtained in studies of flake outline variability (Borel et al., 2017, 2013; Byrne et al., 2016; Rezek et al., 2011).

The examination of morphological variation by PCA indicated that blades produced by different techniques overlap in the (outline) morphology, supporting the results of previous studies (e.g. Damlien, 2015; Sollberger and Patterson, 1976). This conclusion is supported by discriminant analyses that performed considerably better than chance, but with the classification accuracy still relatively low for predicting the knapping technique of individual blades from the archaeological record. The mean overall classification accuracy of $64.8 \%$ is slightly higher than in the previous study of blades based on qualitative features (Damlien, 2015 - 54.5\%), and a bit lower than the correct classification rate for soft stone and pressure flakes in the study of Buchanan et al. (2016 
- 70\%), where several linear measurements were used as independent variables. Although the differing number of groups in these studies impedes proper comparability, it seems that the EFA has a similar predicting power for discriminating between the knapping techniques as the previously proposed approaches.

Despite the overlap in the shape of individual blades, certain morphological differences on the group level were noted. Blades produced by indirect percussion and particularly pressure debitage are generally narrower and have less side-to-side curvature than the blades produced by direct percussion. This is in line with the results of Buchanan et al. (2016), who concluded that pressure flakes are narrower than soft hammer direct percussion flakes. Furthermore, although the majority of blades have similar proximal and distal width, some blades produced by direct percussion have maximal width located in the distal part of the blades, while some pressure blades have wider proximal parts. Inizian et al. (Inizian et al., 1999, p. 79) made a similar insight when discussing the morphology of pressure blades arguing that their "maximum width ... is very rapidly reached".

Our research hypothesis about blade regularity that was based on previous insights (e.g. Pelegrin 2006) is supported by this study, as indicated by multidimensional Euclidean distances, coefficients of variation, symmetry values, and visual examination of PCA plots. Pressure blades are more symmetrical than the other two groups of blades and have regularity similar to indirect percussion blades, but higher than direct percussion blades. Indirect percussion blades have higher symmetry and standardization than direct percussion blades, as predicted. In the case of flakes, using several linear measurements Buchanan et al. (2016) also determined that those produced by pressure are more standardized than soft stone percussion flakes. Interestingly, they reached a different conclusion in the case of symmetry, concluding that the two groups have comparable levels of symmetry. However, our opinion is that the measure they utilized does not measure the bilateral symmetry, but the distribution of surface area relative to the long axis of flakes. As previously acknowledged, higher regularity of indirect percussion blades and particularly pressure blades might be related to a higher degree of control and precision during the detachment (e.g. Andrefsky, 1998, p. 12; Dibble and Whittaker, 1981).

Our results indicate that there is a relationship between the size and shape/symmetry of blades. Therefore, size should be considered an important aspect when analyzing blade variability. 
Additionally, we noted that the blades produced by different modes of pressure differ in terms of outline shape and regularity, supplementing the previous insights (Pelegrin, 2012). This implies that the commonly used categories of knapping techniques (direct, indirect, pressure) are not always suitable for understanding past human behavior, as they incorporate a plethora of factors that may influence the blade variability (e.g. mode of pressure, core size and morphology, indentor properties; see Supplementary material 5 for insights into inter-technique variability). Controlled knapping experiments (see Rezek et al., 2016 and references therein) will probably elucidate this complex interplay of factors that influence the flake/blade variability. However, before getting more profound insights about the causes and consequences in lithic studies, GMM and other quantitative approaches provide suitable frameworks for quantitatively exploring the empirical patterns of variability.

We consider that EFA is suitable for exploring blade outline variability, and for rough assessment of the predominant knapping technique(s) on assemblage-level and tracking relative changes in their use, in a similar manner as proposed by Damlien (2015). As mentioned, the question of knapping techniques is more complex, and this approach might only indicate certain possibilities and exclude others. Both archaeological and experimental collections can be compared in shape and regularity using statistical tools and visualizations applied in this study. There are some advantages of using EFA: 1) it can be applied to photographs, which makes it efficient in terms of time and effort (e.g. McPherron and Dibble, 1999), although this does depend on the quality of photographs - in the case of high-quality images of with easily distinguishable backgrounds, the data acquisition process is very quick, and can even be automated (see import_jpg function in Momocs package), while low-quality images of blades with similarly colored backgrounds usually require extensive editing; 2) it is suitable for quantitatively describing, comparing, and visualizing the similarities and differences in shape and regularity, without discretization (e.g. regular/irregular); 3) it facilitates data transparency and method repeatability (Marwick, 2017; Marwick et al., 2017), which makes it particularly suitable for large-scale comparisons. Nevertheless, we consider that standard technological analysis provides a deeper understanding of past human behavior when done by lithic experts (e.g. Pelegrin, 2006), especially as it investigates multiple aspects of shape not covered in this study (e.g. bulb of percussion, profile curvature, mesial belly). Two methods could be used as 
complementary - inferences obtained using EFA could be tested using detailed technological analysis and vice versa.

Having said that, before EFA becomes a standard tool for describing the blade variability, more research on measurement error should be undertaken. Furthermore, although we included blades produced by several individuals so our results should be fairly robust and generalizable, they should be further tested by other researchers, preferably with more balanced samples. Regarding other directions for further research, the influence of other factors on blade outline variability could be investigated (e.g. core morphology, individual factors, raw materials, skill), and how to deal with the fragmentation of archaeological finds. As this approach neglects the $3^{\text {rd }}$ dimension, one of the key areas for further research could be the application of 3D GMM approaches (e.g. Chacón et al., 2016; Delpiano and Uthmeier, 2020; Herzlinger and Grosman, 2018), to quantitatively examine other important aspects of variability, related to thickness, profile curvature, bulb features, etc.

In this study, we quantitatively tested certain assumptions regarding the blade shape and regularity, and built upon the quantitative descriptions of blade variability related to the knapping technique. Although we highlight the need for more research on the validity of this method, we consider our results to show the potential of EFA for describing and explaining the patterns of blade variability. It could be used in combination with the standard technological analysis for making more sound inferences about the past knapping behavior. With this pilot study, we hope to stimulate research on the application of novel quantitative methods to prismatic blades.

\section{Acknowledgments}

We would like to thank Professor Marko Porčić for useful comments and suggestions on the study design and the manuscript. We also thank two anonymous reviewers for their insightful and constructive comments and suggestions.

Funding Source Declaration: The work of Mihailo Radinović is supported by the Ministry of Education, Science and Technological Development of the Republic of Serbia. 


\section{CRediT roles:}

Mihailo Radinović: Conceptualization, Data curation, Formal analysis, Investigation, Software, Visualization, Project administration, Validation, Writing - original draft, review \& editing.

Irina Kajtez: Conceptualization, Data curation, Investigation, Software, Visualization, Writing review \& editing.

\section{References}

Anderson, M.J., Walsh, D.C.I., 2013. PERMANOVA, ANOSIM, and the Mantel test in the face of heterogeneous dispersions: What null hypothesis are you testing? Ecological Monographs 83, 557-574. https://doi.org/10.1890/12-2010.1

Andrefsky, W.J., 1998. Lithics: Macroscopic Approaches to Analysis. Cambridge, Cambridge University Press. https://doi.org/10.1017/CBO9780511810244

Archer, W., Gunz, P., Niekerk, K.L. van, Henshilwood, C.S., McPherron, S.P., 2015. Diachronic Change within the Still Bay at Blombos Cave, South Africa. PLOS ONE 10, e0132428. https://doi.org/10.1371/journal.pone.0132428

Archer, W., Pop, C.M., Rezek, Z., Schlager, S., Lin, S.C., Weiss, M., Dogandžić, T., Desta, D., McPherron, S.P., 2018. A geometric morphometric relationship predicts stone flake shape and size variability. Archaeol Anthropol Sci 10, 1991-2003. https://doi.org/10.1007/s12520-017-0517-2

Arnqvist, G., Mårtensson, T., 1998. Measurement error in geometric morphometrics: Empirical strategies to assess and reduce its impact on measures of shape. Acta Zoologica Academiae Scientiarum Hungaricae 44, 73-96.

Bar-Yosef, O., Kuhn, S.L., 1999. The Big Deal about Blades: Laminar Technologies and Human Evolution. American Anthropologist 101, 322-338. https://doi.org/10.1525/aa.1999.101.2.322

Boldurian, A.T., Hoffman, E.E., 2009. Clovis Blade Manufacture: Analytical Procedure to Infer "Technique." North American Archaeologist 30, 167-194. https://doi.org/10.2190/NA.30.2.d

Bonhomme, V., Picq, S., Gaucherel, C., Claude, J., 2014. Momocs : outline analysis using R. Journal of Statistical Software 56, 24 p. https://doi.org/10.18637/jss.v056.i13

Borel, A., Cornette, R., Baylac, M., 2017. Stone Tool Forms and Functions: A Morphometric Analysis of Modern Humans' Stone Tools From Song Terus Cave (Java, Indonesia). Archaeometry 59, 455-471. https://doi.org/10.1111/arcm.12264

Borel, A., Gaillard, C., Moncel, M.-H., Sala, R., Pouydebat, E., Simanjuntak, T., Sémah, F., 2013. How to interpret informal flakes assemblages? Integrating morphological description, usewear and morphometric analysis gave better understanding of the 
behaviors of anatomically modern human from Song Terus (Indonesia). Journal of Anthropological Archaeology 32, 630-646. https://doi.org/10.1016/j.jaa.2013.03.002

Buchanan, B., Mraz, V., Eren, M.I., 2016. ON IDENTIFYING STONE TOOL PRODUCTION TECHNIQUES: AN EXPERIMENTAL AND STATISTICAL ASSESSMENT OF PRESSURE VERSUS SOFT HAMMER PERCUSSION FLAKE FORM. American Antiquity 81, 737-751. DOI: 10.7183/0002-7316.81.4.737

Buchanan, B., O’Brien, M.J., Collard, M., 2014. Continent-wide or region-specific? A geometric morphometrics-based assessment of variation in Clovis point shape. Archaeol Anthropol Sci 6, 145-162. https://doi.org/10.1007/s12520-013-0168-x

Byrne, F., Proffitt, T., Arroyo, A., de la Torre, I., 2016. A comparative analysis of bipolar and freehand experimental knapping products from Olduvai Gorge, Tanzania. Quaternary International, New approaches to the study of Quartz lithic industries 424, 58-68. https://doi.org/10.1016/j.quaint.2015.08.018

Caple, J., Byrd, J., Stephan, C.N., 2017. Elliptical Fourier analysis: fundamentals, applications, and value for forensic anthropology. Int J Legal Med 131, 1675-1690. https://doi.org/10.1007/s00414-017-1555-0

Cardini, A., 2014. Missing the third dimension in geometric morphometrics: how to assess if 2D images really are a good proxy for 3D structures? Hystrix, the Italian Journal of Mammalogy 25. https://doi.org/10.4404/hystrix-25.2-10993

Cardini, A., Chiapelli, M., 2020. How flat can a horse be? Exploring 2D approximations of 3D crania in equids. Zoology 139, 125746. https://doi.org/10.1016/j.zool.2020.125746

Chacón, M.G., Détroit, F., Coudenneau, A., Moncel, M.-H., 2016. Morphometric Assessment of Convergent Tool Technology and Function during the Early Middle Palaeolithic: The Case of Payre, France. PLOS ONE 11, e0155316. https://doi.org/10.1371/journal.pone.0155316

Clark, J.E., 2012. Stoneworkers' Approaches to Replicating Prismatic Blades, in: Desrosiers, P.M. (Ed.), The Emergence of Pressure Blade Making: From Origin to Modern Experimentation. Springer US, Boston, MA, pp. 43-135. https://doi.org/10.1007/978-14614-2003-3_3

Clarkson, C., Hiscock, P., 2011. Estimating original flake mass from 3D scans of platform area. Journal of Archaeological Science 38, 1062-1068. https://doi.org/10.1016/j.jas.2010.12.001

Costa, A.G., 2010. A Geometric Morphometric Assessment of Plan Shape in Bone and Stone Acheulean Bifaces from the Middle Pleistocene Site of Castel di Guido, Latium, Italy, in: Lycett, S., Chauhan, P. (Eds.), New Perspectives on Old Stones: Analytical Approaches to Paleolithic Technologies. Springer, New York, NY, pp. 23-41. https://doi.org/10.1007/978-1-4419-6861-6_2

Cotterell, B., Kamminga, J., 1987. The Formation of Flakes. American Antiquity 52, 675-708. https://doi.org/10.2307/281378

Crabtree, D.E., 1968. Mesoamerican Polyhedral Cores and Prismatic Blades. American Antiquity 33, 446-478. https://doi.org/10.2307/278596

Crampton, J.S., 1995. Elliptic Fourier shape analysis of fossil bivalves: some practical considerations. Lethaia 28, 179-186. https://doi.org/10.1111/j.1502-3931.1995.tb01611.x

Damlien, H., 2015. Striking a difference? The effect of knapping techniques on blade attributes. Journal of Archaeological Science 63, 122-135. https://doi.org/10.1016/j.jas.2015.08.020 
Davidson, I., 2003. 'Part and parcel' — blade industries and modern human behaviour. Australian Archaeology 57, 54-63. https://doi.org/10.1080/03122417.2003.11681762

Debenath, A., Dibble, H.L., 1994. Handbook of Paleolithic Typology: Lower and Middle Paleolithic of Europe. UPenn Museum of Archaeology.

Delagnes, A., Meignen, L., 2006. Diversity of Lithic Production Systems During the Middle Paleolithic in France, in: Hovers, E., Kuhn, S.L. (Eds.), Transitions Before the Transition: Evolution and Stability in the Middle Paleolithic and Middle Stone Age, Interdisciplinary Contributions To Archaeology. Springer US, Boston, MA, pp. 85-107. https://doi.org/10.1007/0-387-24661-4_5

Delpiano, D., Uthmeier, T., 2020. Techno-functional and 3D shape analysis applied for investigating the variability of backed tools in the Late Middle Paleolithic of Central Europe. PLOS ONE 15, e0236548. https://doi.org/10.1371/journal.pone.0236548

Dibble, H.L., Rezek, Z., 2009. Introducing a new experimental design for controlled studies of flake formation: results for exterior platform angle, platform depth, angle of blow, velocity, and force. Journal of Archaeological Science 36, 1945-1954. https://doi.org/10.1016/j.jas.2009.05.004

Dibble, H.L., Whittaker, J.C., 1981. New experimental evidence on the relation between percussion flaking and flake variation. Journal of Archaeological Science 8, 283-296. https://doi.org/10.1016/0305-4403(81)90004-2

Driscoll, K., García-Rojas, M., 2014. Their lips are sealed: identifying hard stone, soft stone, and antler hammer direct percussion in Palaeolithic prismatic blade production. Journal of Archaeological Science 47, 134-141. https://doi.org/10.1016/j.jas.2014.04.008

Ferson, S., Rohlf, F.J., Koehn, R.K., 1985. Measuring Shape Variation of Two-dimensional Outlines. Systematic Biology 34, 59-68. https://doi.org/10.1093/sysbio/34.1.59

Fox, A.N., 2015. A study of Late Woodland projectile point typology in New York using elliptical Fourier outline analysis. Journal of Archaeological Science: Reports 4, 501509. https://doi.org/10.1016/j.jasrep.2015.10.022

Fruciano, C., 2016. Measurement error in geometric morphometrics. Dev Genes Evol 226, 139158. https://doi.org/10.1007/s00427-016-0537-4

Herzlinger, G., Goren-Inbar, N., Grosman, L., 2017. A new method for 3D geometric morphometric shape analysis: The case study of handaxe knapping skill. Journal of Archaeological Science: Reports 14, 163-173. https://doi.org/10.1016/j.jasrep.2017.05.013

Herzlinger, G., Grosman, L., 2018. AGMT3-D: A software for 3-D landmarks-based geometric morphometric shape analysis of archaeological artifacts. PLOS ONE 13, e0207890. https://doi.org/10.1371/journal.pone.0207890

Hoggard, C.S., McNabb, J., Cole, J.N., 2019. The Application of Elliptic Fourier Analysis in Understanding Biface Shape and Symmetry Through the British Acheulean. J Paleo Arch 2, 115-133. https://doi.org/10.1007/s41982-019-00024-6

Inizian, M.-L., Reduron-Ballinger, M., Roche, H., Tixier, J., 1999. Technology and Terminology of Knapped Stone. Nanterre: CREP.

Iovita, R., McPherron, S.P., 2011. The handaxe reloaded: A morphometric reassessment of Acheulian and Middle Paleolithic handaxes. Journal of Human Evolution 61, 61-74. https://doi.org/10.1016/j.jhevol.2011.02.007 
Iwata, H., Niikura, S., Matsuura, S., Takano, Y., Ukai, Y., 1998. Evaluation of variation of root shape of Japanese radish (Raphanus sativus L.) based on image analysis using elliptic Fourier descriptors. Euphytica 102, 143-149. https://doi.org/10.1023/A:1018392531226

Johnson, C.R., McBrearty, S., 2010. 500,000 year old blades from the Kapthurin Formation, Kenya. J. hum. evol 58, 193-200.

Klingenberg, C.P., 2015. Analyzing Fluctuating Asymmetry with Geometric Morphometrics: Concepts, Methods, and Applications. Symmetry 7, 843-934. https://doi.org/10.3390/sym7020843

Krishnamoorthy, K., Lee, M., 2014. Improved tests for the equality of normal coefficients of variation. Computational Statistics, 29(1), 215-232. https://doi.org/10.1007/s00180-0130445-2

Kooyman, B.P., 2000. Understanding Stone Tools and Archaeological Sites. UNM Press.

Kovarovic, K., Aiello, L.C., Cardini, A., Lockwood, C.A., 2011. Discriminant function analyses in archaeology: are classification rates too good to be true? Journal of Archaeological Science 38, 3006-3018. https://doi.org/10.1016/j.jas.2011.06.028

Kuhl, F.P., Giardina, C.R., 1982. Elliptic Fourier features of a closed contour. Computer Graphics and Image Processing 18, 236-258. https://doi.org/10.1016/0146$\underline{664 X(82) 90034-X}$

Lengyel, G., Chu, W., 2016. Long thin blade production and Late Gravettian hunter-gatherer mobility in Eastern Central Europe. Quaternary International, The Lithic Issues of the Gravettian 406, 166-173. https://doi.org/10.1016/j.quaint.2016.01.020

Lestrel, P.E., 1997. Fourier Descriptors and Their Applications in Biology. Cambridge University Press.

Lycett, S.J., Cramon-Taubadel, N. von, Gowlett, J.A.J., 2010. A comparative 3D geometric morphometric analysis of Victoria West cores: implications for the origins of Levallois technology. Journal of Archaeological Science 37, 1110-1117. https://doi.org/10.1016/j.jas.2009.12.011

Lycett, S.J., von Cramon-Taubadel, N., 2013. A 3D morphometric analysis of surface geometry in Levallois cores: patterns of stability and variability across regions and their implications. Journal of Archaeological Science 40, 1508-1517. https://doi.org/10.1016/j.jas.2012.11.005

Magnani, M., Rezek, Z., Lin, S.C., Chan, A., Dibble, H.L., 2014. Flake variation in relation to the application of force. Journal of Archaeological Science 46, 37-49. https://doi.org/10.1016/j.jas.2014.02.029

Martinez Arbizu, P., 2017. pairwiseAdonis: Pairwise multilevel comparison using adonis. R package version 0.01 .

Marwick, B., 2017. Computational Reproducibility in Archaeological Research: Basic Principles and a Case Study of Their Implementation. J Archaeol Method Theory 24, 424-450. https://doi.org/10.1007/s10816-015-9272-9

Marwick, B., d'Alpoim Guedes, J., Barton, C.M., Bates, L.A., Baxter, M., Bevan, A., Bollwerk, E.A., Bocinsky, R.K., Brughmans, T., Carter, A.K., Conrad, C., Contreras, D.A., Costa, S., Crema, E.R., Daggett, A., Davies, B., Drake, B.L., Dye, T.S., France, P., Fullagar, R., Giusti, D., Graham, S., Harris, M.D., Hawks, J., Health, S., Huffer, D., Kansa, E.C., Kansa, S.W., Madsen, M.E., Melcher, J., Negre, J., Neiman, F.D., Opitz, R., Orton, D.C., Przstupa, P., Raviele, M., Riel-Savatore, J., Riris, P., Romanowska, I., Smith, J., Strupler, N., Ullah, I.I., Van Vlack, H.G., VanValkenburgh, N., Watrall, E.C., Webster, C., Wells, 
J., Winters, J., Wren, C.D., 2017. Open science in archaeology. SAA Archaeological Record 17, 8-14.

Marwick, B., Krishnamoorthy., K., (2019). cvequality: Tests for the Equality of Coefficients of Variation from Multiple Groups. R package version 0.2.0. https://CRAN.Rproject.org/package $=$ cvequality

McBrearty, S., Brooks, A.S., 2000. The revolution that wasn't: a new interpretation of the origin of modern human behavior. Journal of Human Evolution 39, 453-563. https://doi.org/10.1006/jhev.2000.0435

McPherron, S.P., Dibble, H.L., 1999. Stone Tool Analysis Using Digitized Images: Examples from the Lower and Middle Paleolithic. Lithic Technology 24, 38-52. https://doi.org/10.1080/01977261.1999.11720944

Muller, A., Clarkson, C., 2014. Estimating original flake mass on blades using 3D platform area: problems and prospects. Journal of Archaeological Science 52, 31-38. https://doi.org/10.1016/j.jas.2014.08.025

Muller, A., Clarkson, C., Shipton, C., 2017. Measuring behavioural and cognitive complexity in lithic technology throughout human evolution. Journal of Anthropological Archaeology 48, 166-180. https://doi.org/10.1016/j.jaa.2017.07.006

Navarro, N., Maga, A.M., 2016. Does 3D Phenotyping Yield Substantial Insights in the Genetics of the Mouse Mandible Shape? G3 Genes|Genomes|Genetics 6, 1153-1163. https://doi.org/10.1534/g3.115.024372

Oksanen, J., Blanchet, F.G., Friendly, M., Kindt, R., Legendre, P., McGlinn, D., Minchin, P.R., O’Hara, R.B., Simpson, G.L., Solymos, P., Stevens, M.H.H., Szoecs, E., Wagner, H., 2020. vegan: Community Ecology Package.

Okumura, M., Araujo, A.G.M., 2019. Archaeology, biology, and borrowing: A critical examination of Geometric Morphometrics in Archaeology. Journal of Archaeological Science 101, 149-158. https://doi.org/10.1016/j.jas.2017.09.015

Pelcin, A., 1997a. The Effect of Indentor Type on Flake Attributes: Evidence from a Controlled Experiment. Journal of Archaeological Science 24, 613-621. https://doi.org/10.1006/jasc.1996.0145

Pelcin, A., 1997b. The Formation of Flakes: The Role of Platform Thickness and Exterior Platform Angle in the Production of Flake Initiations and Terminations. Journal of Archaeological Science 24, 1107-1113. https://doi.org/10.1006/jasc.1996.0190

Pelcin, A., 1997c. The Effect of Core Surface Morphology on Flake Attributes: Evidence from a Controlled Experiment. Journal of Archaeological Science 24, 749-756. https://doi.org/10.1006/jasc.1996.0156

Pelegrin, J., 2012. New Experimental Observations for the Characterization of Pressure Blade Production Techniques, in: Desrosiers, P.M. (Ed.), The Emergence of Pressure Blade Making: From Origin to Modern Experimentation. Springer US, Boston, MA, pp. 465500. https://doi.org/10.1007/978-1-4614-2003-3_18

Pelegrin, J., 2006. Long blade technology in the Old World: an experimental approach and some archaeological results, in: Skilled Production and Social Reproduction, SAU Stone Studies. Societas Archaeologica Upsaliensis, Uppsala, pp. 37-68.

Pelegrin, J., 1990. Prehistoric Lithic Technology: Some Aspects of Research. Archaeological review from Cambridge 9, 116-125. 
Pelegrin, J., Inizan, M.-L., 2013. Soft hammerstone percussion use in bidirectional blade-tool production at Acila 36 and in bifacial knapping at Shagra (Qatar). Arabian Archaeology and Epigraphy 24, 79-86. https://doi.org/10.1111/aae.12016

Perlès, C., 2001. The Early Neolithic in Greece: The First Farming Communities in Europe. Cambridge University Press.

Picin, A., Vaquero, M., Weniger, G.-C., Carbonell, E., 2014. Flake morphologies and patterns of core configuration at the Abric Romaní rock-shelter: A geometric morphometric approach. Quaternary International, Lithics of the Late Middle Palaeolithic: Post MIS 5 technological variability and its implications 350, 84-93. https://doi.org/10.1016/j.quaint.2014.05.004

R Core Team, 2020. R: A language and environment for statistical computing. $\mathrm{R}$

Foundation for Statistical Computing, Vienna, Austria. https://www.R-project.org/.

Rezek, Z., Lin, S., Dibble, H., 2016. The role of controlled experiments in understanding variation in flake production. Faculty of Science, Medicine and Health - Papers: part A 307-320.

Rezek, Z., Lin, S., Iovita, R., Dibble, H.L., 2011. The relative effects of core surface morphology on flake shape and other attributes. Journal of Archaeological Science 38, 1346-1359. https://doi.org/10.1016/j.jas.2011.01.014

Riede, F., Hoggard, C., Shennan, S., 2019. Reconciling material cultures in archaeology with genetic data requires robust cultural evolutionary taxonomies. Palgrave Communications 5, 1-9. https://doi.org/10.1057/s41599-019-0260-7

Rohlf, F.J., 2019. tpsUtil-TPS utility program. State University at Stony Brook, Stony Brook, NY.

Rohlf, F.J., 2017. TPS Dig computer program. Stony Brook, New York.

Ruck, L., Holden, C., Putt, S.S.J., Schick, K., Toth, N., 2020. Inter- and Intra-rater Reliability in Lithic Analysis: a Case Study in Handedness Determination Methodologies. J Archaeol Method Theory 27, 220-244. https://doi.org/10.1007/s10816-019-09424-y

Sheets, H.D., Covino, K.M., Panasiewicz, J.M., Morris, S.R., 2006. Comparison of geometric morphometric outline methods in the discrimination of age-related differences in feather shape. Frontiers in Zoology 3, 15. https://doi.org/10.1186/1742-9994-3-15

Shimelmitz, R., Barkai, R., Gopher, A., 2011. Systematic blade production at late Lower Paleolithic (400-200 kyr) Qesem Cave, Israel. Journal of Human Evolution 61, 458-479. https://doi.org/10.1016/j.jhevol.2011.06.003

Slice, D.E., 2005. Modern Morphometrics, in: Slice, D.E. (Ed.), Modern Morphometrics in Physical Anthropology, Developments in Primatology: Progress and Prospects. Springer US, Boston, MA, pp. 1-45. https://doi.org/10.1007/0-387-27614-9_1

Sollberger, J.B., Patterson, L.W., 1976. Prismatic Blade Replication. American Antiquity 41, 517-531. https://doi.org/10.2307/279021

Sørensen, M., 2006. Rethinking the lithic blade definition: towards a dynamic understanding, in: Skilled Production and Social Reproduction, SAU Stone Studies. Societas Archaeologica Upsaliensis, Uppsala, pp. 277-296.

Soriano, S., Villa, P., Wadley, L., 2007. Blade technology and tool forms in the Middle Stone Age of South Africa: the Howiesons Poort and post-Howiesons Poort at Rose Cottage Cave. Journal of Archaeological Science 34, 681-703. https://doi.org/10.1016/j.jas.2006.06.017 
Wang, L.Y., Marwick, B., 2020. Standardization of ceramic shape: A case study of Iron Age pottery from northeastern Taiwan. Journal of Archaeological Science: Reports, 33, p.102554. https://doi.org/10.1016/j.jasrep.2020.102554

Wickham, H., 2016. Package 'ggplot2.' Create Elegant Data Visualisations Using the Grammar of Graphics. Version 2, 1-189.

Wickham, H., 2007. Reshaping Data with the reshape Package. Journal of Statistical Software 21, 1-20. https://doi.org/10.18637/jss.v021.i12

Wickham, H., François, R., Henry, L., Müller, K., RStudio, 2021. dplyr: A Grammar of Data Manipulation.

Wilke, C.O., 2020. cowplot: streamlined plot theme and plot annotations for 'ggplot2'. R package version 0.9. 2; 2017. https://CRAN.R-project.org/package=cowplot

Wilkins, J., Chazan, M., 2012. Blade production 500 thousand years ago at Kathu Pan 1, South Africa: support for a multiple origins hypothesis for early Middle Pleistocene blade technologies. Journal of Archaeological Science 39, 1883-1900. https://doi.org/10.1016/j.jas.2012.01.031

Williams, J.P., Andrefsky, W., 2011. Debitage variability among multiple flint knappers. Journal of Archaeological Science 38, 865-872. https://doi.org/10.1016/j.jas.2010.11.008

Zelditch, M.L., Swiderski, D.L., Sheets, H.D., 2012. Geometric Morphometrics for Biologists: A Primer. Academic Press. 